\title{
Complaints and compliments assessment in developing service delivery measurement
}

\author{
Norshahrizan Nordin ${ }^{a^{*}}$, Wan Norsyafawati W. Muhamad Radzi ${ }^{\text {b }, \text { Razli Che Razak }}{ }^{\mathrm{c}}$, Sharmini \\ Abdullah $^{d}$, Mohammad Rezal Hamzah ${ }^{\mathrm{e}}$, Ummi Naiemah Saraih ${ }^{\mathrm{f}}$ and Syed Zulkarnain Syed \\ Idrus $^{g}$
}

${ }^{a, b}$ School of Business Innovation \& Technopreneurship, Universiti Malaysia Perlis, Malaysia

${ }^{c}$ Faculty of Entrepreneurship and Management, Universiti Malaysia Kelantan, Malaysia

${ }^{d}$ Centre of International Languages, Universiti Malaysia Perlis, Malaysia

e,g School of Human Development \& Techno Communication, Universiti Malaysia Perlis, Malaysia

${ }^{f}$ School of Business Innovation \& Technopreneurship, Universiti Malaysia Perlis, Malaysia

\section{H R O N I C L E}

\section{Article history:}

Received: November 26, 2017

Received in revised format:

March 31, 2018

Accepted: April 4, 2018

Available online:

April 5, 2018

Keywords:

Complaint

Compliment

Satisfaction

Dissatisfaction

Service Delivery

Kano Model

\section{A B S T R A C T}

\begin{abstract}
Excellent healthcare services delivered to patients would not necessarily entail an excellent patient service fulfillment, fulfill patient expectations, and attain high satisfaction levels. Hence, patient satisfaction is multifactorial and difficult to measure. Appliance of satisfaction model, service dissatisfaction and satisfaction feedback are able to translate the non-linear attributes for a more accurate service dissatisfaction and satisfaction feedback assessment. Service recipients of experienced Inpatient and Outpatient (IOPs) can be translated into levels of compliments and complaints to describe degrees of patient satisfaction and dissatisfaction, respectively. Compliments and complaints voiced by patients should be taken seriously. As a result, the translation of service satisfaction and service dissatisfaction based on compliments and complaints from patients in the form of satisfaction index SCi and dissatisfaction index SCa introduced a new theoretical concept of concurrent and balance measurement in evaluating customer (VOC) or VOPs feedback. In normal practice, the service improvement is usually based on complaints or dissatisfaction aspect, but the compliments or satisfaction aspect on the same service delivery was always neglected. In this study, the formulation which was based on a non-linear assessment, not only amplified the effectiveness in communicating patients' compliments and complaints in a more receptive manner but also corresponded with Kano model.
\end{abstract}

\section{Introduction}

Complaint handling has a significant effect on customer retention rates, word-of-mouth recommendations (Yuksel et al., 2006), and cultural impact for embarrassing service failure (Wan, 2013). In order to reduce complaints in healthcare service, several past studies have measured enormous service quality attributes to understand the gap between patient expectations and service delivery. For example, Camilleri and O'Callaghan (1998) measured six service quality attributes, namely catering, hospital envi-

\footnotetext{
* Corresponding author.

E-mail address: norshahrizan@unimap.edu.my (N. Nordin) 
ronment, professional and technical quality, patient amenities, service personalization, and accessibility. The study developed a methodology to measure the overall service quality, service meeting, needs and demands of patients in public and private hospitals in Malta. Findings revealed patients gave top ranking to professional and technical care as a basis demand services indicator for both public and private sectors. The high frequency of complaints were mainly related to communication, attitude, waiting time, organizational of service, medical care, and nursing care. Complaints occur as a result of poor communication, raised and unfulfilled expectations, and differing perceptions. Normally, complainants seek for explanation, apology, and assurance that what happened to them would not happen to anyone else (Scott, 2003; Baba, 2011). Some complainants are motivated by money, rewards basis, and wish to see that a particular staff gets punished for what they did. Furthermore, complaints can be classified into internal and external complaints. Internal complaints come from healthcare colleagues and other members of staff (Baba, 2011). Most of the complaints are about managerial matters, but rarely about patient care. However, the most upsetting is patient complaints, which is classified as external complaints (Scott, 2003). Complaints are addressed as formal and informal complaints. Most of the important complaints are normally discussed amongst the public, informally. Besides, many healthcare consultants do not understand why patients and their relatives find it difficult to voice their concerns on the quality of service. Patients are also genuinely fearful in criticizing their doctors because they do not want to risk their future treatments that might be compromised. Hence, patients do not discuss their fears and concerns. Besides, it is easier and more productive for the patients or their relatives to discuss their concerns with someone else who is independent. This approach had been proven successful with the setup of Patient Advocacy Liaison Service (PALS) in Conquest Hospital (Scott, 2003).

In the Malaysian healthcare service, delivery, poor communication was one of the main causes for complaints (Baba, 2011; Wah, 2011). In responding to complaints, the complainant would usually expect an explanation, an apology, and an assurance that what happened to them would not happen to anyone else. Many formal complaints could be prevented if the clinicians made themselves readily available and spoke to patients and their relatives using appropriate language. In other words, there is a need to check and follow up with patients and their relatives to ensure that they really understood what they had been told. In a separate study, Mohd Suki et al. (2011) carried out an investigation to identify the level of customers' satisfaction with service quality in Malaysia that was provided by a healthcare setting, specifically in the Klang Valley areas. The study investigated if patients' perceptions exceeded expectations when they sought treatment in private hospitals based on service gaps determination. Eight quality dimensions of service gaps were defined as variables, namely reliability, tangibility, responsiveness, assurance, empathy, courtesy, communication, and customer understanding (Parasuraman, 2002). The results pointed out that variable assurance provided by Malaysian private healthcare hospitals attained the highest score. In other words, patients' perceptions exceeded expectations in terms of treatments, information sharing, and clarity in explanations if medical conditions were well-practiced. Meanwhile, the lowest score had been from responsiveness, followed by empathy, and communication. Failure in delivering empathy was related to feedback mechanism to keep customer informed and the level of doctors or staff understanding of customer needs. Furthermore, failure in communication demonstrated the weak point of service delivery particularly in demonstrating concern, listening to customers' health problems and understanding them. Findings also revealed that the healthcare staff were unable to react quickly with scheduled appointment changes and treatment query (Mohd Suki et al., 2011). Customer satisfaction has become a source of competitive advantage. It has been used as a satisfaction rating towards performance indicator of many firms' future businesses. Kano model distinguishes three types of product or services requirements that influence customer satisfaction (Kano, 1984). A recent review of Kano model application highlighted that literature concerning healthcare service, only Jané and Domínguez's (2003) model of customer satisfaction was presented till the year 2010. Apart from that, model of quality, model of customer requirement, model of product design, model of customer needs, model of product development, model of product planning, and model of product improvement were also presented as well. 


\section{Literature Review}

Malaysian healthcare capacity and constraints are paramount reasons for the rise of service satisfaction and dissatisfaction, which contributed to the increment of service complaints and reduction of compliments, respectively. According to Malaysian National Healthcare Statistics Initiative report by Abdullah et al. (2011) from 2008-2009, MOH revealed that present problems affecting the MOH workforce, include shortage of skilled personnel, movement of health professionals from the public sector to the private sector, inadequate expertise in some critical areas, and difficulty in placement and retention of doctors and nurses in more remote areas (Baba, 2011; Baba et al., 2011). Moreover, the government also acknowledged that the misdistribution of health personnel had created an imbalance of service distribution in rural areas, such as in Sabah and Sarawak. This is because; they are mainly concentrated in the urban areas (Onn et al., 2014). According to Abdel Hakim Rateb et al. (2011), healthcare is also influenced by internal and external forces, such as reimbursement changes, political landscape, and economic changes. In the United States of America, the healthcare industry faced rapid medical technological advancement and unsustainable inflation in the cost of care that proved to be constraints to HSPs (Powell \& Laufer, 2010).

\subsection{Complaints and Compliments in Healthcare Service}

Complaints are defined as a result of failed expectations (Scott, 2003; Henneberg et al., 2009) and perceived negatively by service dissatisfaction (Jangland et al., 2009; Gandhi et al., 2018). Complaints by dissatisfied patients actually provides opportunities for managers to gain a better insight of the problems and take corrective actions for improvement (Namkung et al., 2011). Perceptions refer to the patients' evaluation of the service provided, as good quality of services will result in a positive perception, while poor service will entail a negative perception (Cheng Lim, \& Tang, 2000). Expectation is the central of satisfaction (Coye, 2004) and perception can disconfirm expectations for worse or better or confirm it as neutral (Mohd Suki et al., 2011). Hence, service dissatisfaction can be referred as a negative perception of poor service quality that fails to exceed patients' expectation, which is expressed through complaints or medication satisfaction claim (Shikiar \& Rentz, 2004). In this case, service performance is noted as a low service quality. Correspondingly, compliments are defined as a result of exceeding expectations and satisfying consumption (Friman \& Edvardsson, 2003) to express satisfaction. As discussed by Coye (2004), and Cheng Lim and Tang (2000), compliments could also be defined as positive perception of good service that is able to exceed patients' expectation as a result of service satisfaction. This suggests that the service performance is of a high service quality. The service delivery issues in healthcare service quality are normally addressed through which complaints are viewed from the perspectives of customers and clinicians. Besides, the Malaysian National Healthcare Statistics Initiative report outlined that delivery of healthcare and continuous evaluation of healthcare delivery is compulsory for public hospitals in Malaysia. Different hospitals could provide similar services, but they do not provide the same quality of services as expected by customers and healthcare clinicians (Scott, 2003). Delivering poor quality service definitely increases the frequency of complaints from healthcare customers (Rastgar \& Naderi, 2016).

\subsection{Complaints through Public Complaints Bureau (PCB)}

In Malaysia, all complaints, including healthcare complaints are centered through Public Complaints Bureau (PCB), which was setup in 1971, under the Prime Minister's Department. Details of PCB implementation in Malaysia can be found in Teck's (2007) study. As for healthcare complaints, the incremental rise of the frequency of complaints from 2000-2012, which had been gathered from the PCB system. A cumulative of 1592 complaints was made in the year 2012 which portrayed an increase of $156 \%$ from 2011 to 2012 . This fact is apprehensively crucial and demands an investigation. 


\subsection{Complaints through the Malaysian Ministry of Health}

Moreover, the Malaysian Ministry of Health had established a systematic complaint process and procedure to assess complaints from various healthcare stakeholders, particularly patients. The statistics of increased frequency for complaints from 2005 - 2008, adapted from the Corporate Communication Unit in the Ministry of Health (Baba, 2011). It can be observed that from 2006 - 2007, the frequency of complaints increased to 1286 , and from $2007-2008$, the frequency continued to increase by $34.2 \%$. The incremental pattern of complaints observed is identical to the trend which was adapted from the Public Complaints Bureau (PCB). The issue of reducing complaints remained a prioritized agenda. Besides, the fraction of complainants varied. In 2008, for example, 4340 or $86 \%$ of complaints came from IOP, while 168 or $3 \%$ came from MOH staff, and others were 536 or $11 \%$. According to $\mathrm{MOH}$, the main reasons for the cause of complaints were lack of doctors and nurses or medical assistants, and expectations of complainants or patients were unfulfilled (Baba, 2011).

Based on Corporate Communication Unit of $\mathrm{MOH}$ in 2008, there were ten categories of complaints that corresponded to $\mathrm{MOH}$ service delivery in hospitals. The fraction percentage of the total complaints based on the ten categories consists of poor service quality, other complaints, being late and no action, staff misconduct in job, lack of hospital facilities, fail to follow standard procedure (SOP), unfair action, fail of enforcement, power abuse and misused, and failure of laws enforcement. It was observed that poor service quality encountered contributed to the highest rate of complaints, followed by hospital staff professionalism in work, hospital facilities, decision-making and laws enforcement, and limitations. Here, the measurement of service delivery and service recipient proved to be significant factors towards reducing the complaints. Meanwhile, in terms of complaints resources, the varieties of sources where the complaints were configured, such as letter, newspaper, telephone, e-mails, walk-in, e-complaint and others. In addition, it had been found that letters and walks-in were the most popular ways the complaints were addressed to hospitals. In 2007 and 2008, letters were obviously used by complainants to address complaints. This means, IOPs preferred using printed paper based complaints rather than e-complaints. Newspapers, telephones, and e-mails shared almost similar results in terms of frequency from the year 2007-2008. Meanwhile, in order to evaluate the complaints, questionnaire is deemed as the most effective way. The resources of complaints based on the types of public healthcare organizations in Malaysia. Public hospitals were recorded as attaining the highest sources based on the complaints accumulated from the years 2005-2008. This evident proved that public hospitals are a valid source of respondents for this study rather than clinics or institutions.

\subsection{Complaint Issues in Malaysia Healthcare Service Delivery}

Complaint handling provides a significant effect on customer retention rates, word-of-mouth recommendations (Yuksel et al., 2006), and cultural impact for embarrassing service failure (Wan, 2013). In order to reduce complaints in the healthcare service, several past studies have measured enormous service quality attributes to understand the gap between patient expectation and service delivery. For example, Camilleri and O'Callaghan (1998) measured six service quality attributes, namely catering, hospital environment, professional and technical quality, patient amenities, service personalization, and accessibility. The study developed a methodology to measure the overall service quality, service meeting, and needs and demand of patients in public and private hospitals in Malta. It was observed that patients gave top rank to the professional and technical care as a basis demand services indicator for both the public and private sectors. The high category of complaint was related to communication, attitude, waiting time, organizational of service, medical care, and nursing care. Complaints occur as a result of poor communication, raised and unfulfilled expectations, and different perception. Normally, complainants seek for explanation, apology, and assurance that what happened to them would not happen to anyone else (Scott, 2003; Baba, 2011). Some complainants are motivated by money, rewards basis, and wish to see that the particular staff is reprimanded for what they did. 
In Malaysian healthcare service delivery, poor communication was one of the main causes for complaints (Baba, 2011; Wah, 2011). When responding to complaints, the complainant usually wants an explanation, an apology, and an assurance that what happened to them would not happen to anyone else. Many formal complaints could be prevented if the clinicians were more readily available and spoke to patients and their relatives using appropriate language. In other words, there is a need to check with patients and their relatives to ensure that they really understood on what they had been informed.

In a separate study, Mohd Suki et al. (2011) carried out an investigation to identify the level of customers' satisfaction with service quality in Malaysia that was provided by a healthcare setting, specifically in the Klang Valley areas. The study investigated if patients' perceptions exceeded expectations when they sought treatment in private hospitals based on service gaps determination. Eight quality dimensions of service gaps were defined as variables, namely reliability, tangibility, responsiveness, assurance, empathy, courtesy, communication, and customer understanding (Parasuraman, 2002). Findings demonstrated that variable assurance provided by Malaysian private healthcare hospitals gained the highest score, specifically in terms of treatments, information sharing, clarity in explanation and if medical conditions were well-practiced.

Another example in Singapore hospitals, the elements of assurance, tangibility, and responsiveness were the main critical service issues that had been reported by Cheng Lim and Tang (2000). It means that they faced problems concerning friendliness, customer dignity and respect, professionalism among doctors and clinicians, clinicians' willingness, and customers' confidence towards doctors and other healthcare staff. Moreover, even though a substantial number of literatures have suggested the extension of critical service delivery variable, none of them were measured based on non-linear relationship between service delivery and patient expectation based on service fulfillment.

All healthcare researches that proposed the service satisfaction model, were based on linear relationship between service delivery and patient expectation. Primarily, a recent non-linear relationship based on Kano Quality Attribute pioneered by Kano (1984), which was extensively revised as Theory of Quality Attributes and as described by Mikulić and Prebežac (2011), and Theory of Attractive Quality, defined by Löfgren et al. (2011) were looked into. Apart from that, service fulfillment is best to be grounded based on non-linear relationship for a broader dimension of service dissatisfaction and service satisfaction (Chen et al., 2011). Hence, there are still many unexplored dimensions in healthcare service (Singh Gaur et al., 2011).

Meanwhile, the lowest score had been from responsiveness, followed by empathy, and communication. Failure in delivering empathy was related to the feedback mechanism to keep customers informed and the level of doctors or staff receptivity to customer needs. Moreover, failure in communication demonstrated the weak point of service delivery in being concerned and in listening to customers' health problems, as well as in understanding them. This findings also entailed that the healthcare staff were unable to react quickly with scheduled appointment changes and treatment query (Mohd Suki et al. 2011). In addition, Wah (2011) addressed that poor communication was amongst the highest service compliant. In specific care of mental illness and diabetes cases, the professionalism of Malaysian general hospital staff discovered that the attitude of Malaysian general hospital staff varied based on the patients' background. Table 1 summarizes the service delivery issues that were frequently highlighted in healthcare service. 
Table 1

Summary of service delivery variables in healthcare

\begin{tabular}{|c|c|}
\hline Author & Critical Service Delivery Variable Issues in Complaints \\
\hline Camilleri \& O’Callaghan, 1998 & $\begin{array}{l}\text { Catering, hospital environment, professional and technical quality, patient amenities, } \\
\text { service personalization, and accessibility }\end{array}$ \\
\hline Cheng Lim \& Tang, 2000 & $\begin{array}{l}\text { Assurance, tangibility, responsiveness, friendliness, customer dignity and respect, } \\
\text { professionalism among doctors and clinicians, clinicians' willingness, and custom- } \\
\text { ers' confidence }\end{array}$ \\
\hline Scott, 2003 & $\begin{array}{l}\text { Communication, attitude, waiting time, organizational of service, medical care, and } \\
\text { nursing care }\end{array}$ \\
\hline Wu \& Norman, 2006 & Job satisfaction among nurse \\
\hline $\begin{array}{l}\text { Carnevalli \& Miguel, 2008; } \\
\text { Scott, } 2003\end{array}$ & $\begin{array}{l}\text { Professional and technical care (Doctor care, nursing care, medical care, and appa- } \\
\text { ratus used), service personalization (confidentiality, information given, and personal } \\
\text { attention), price, environment (furniture, cleanliness, and general presentation), pa- } \\
\text { tient amenities (comfort, privacy, and visiting hours), accessibility, and catering } \\
\text { (menu, and food quality) }\end{array}$ \\
\hline Jangland et al., 2009 & Encounters and communication \\
\hline Mohd Suki et al., 2011 & $\begin{array}{l}\text { Reliability, tangibility, responsiveness, assurance, empathy, courtesy, communica- } \\
\text { tion, and customer understanding }\end{array}$ \\
\hline $\begin{array}{l}\text { Baba et al. (2011) based on } \\
\text { Malaysian Public Hospital } \\
\text { complaints }\end{array}$ & $\begin{array}{l}\text { Poor service, unpunctual service, clinician's misconduct in work, lack of public fa- } \\
\text { cilities, unfair action, failure in law enforcement, and aberration and limitation of } \\
\text { law in healthcare }\end{array}$ \\
\hline Minas et al. 2011 & Attitude of Malaysian general hospital staff \\
\hline Quaschning et al. (2013 & Medical rehabilitation decision-making (empathy, team work, and team interaction) \\
\hline
\end{tabular}

\subsection{Complaint based on Healthcare Service Delivery Department}

The healthcare service quality issues are viewed differently by customers and clinicians. The perspective of clinicians can be described as the details of what had been claimed by the customers through complaints and translated into more justified technical and functional characteristic (Scott, 2003; Grönroos, 1984). According to Scott (2003), complaints are always a result of failed expectations and by implication, the failure of clinicians to communicate with patients or relatives as to what they should expect. Complaints could be expressed in terms of personal, the team, and the team's modus operandi. The description seems to be more practical for the present study since it mutually matches with the claimed issues made by customers when compared with issues which revolve around with what customers had meant to say happened in hospitals. In public hospitals, most complaints were mainly from the Accident and Emergency department. The fraction of complaint classifications based on the cases from the Conquest Hospital within a 4-year period, 1998-2002. Standard care comprised about half of the total complaints, followed by organization of care (15\%), attitude $(12 \%)$, and appointments $(12 \%)$. Communication (7\%) was one of the issues in complaint. Alternatively, discharge (3\%), admission $(2 \%)$, bereavement $(2 \%)$, and others $(3 \%)$ comprised of the lesser complaints.

\section{Methodology/Materials}

\subsection{Methodological on Service Compliment (SCi) and Service Complaint Indexes (Sca)}

The index of SCa and SCi were inserted into QFD Step 2 according to the defined PAs, orderly. For the case of Surgery Care, Figure 1 shows the information of PAs, SCi and SCa that supply to QFD Phase 2 and 3.

\subsection{Patient's Attributes into QFD (Step 1)}

The first step was to gather the VOPs, known as Patient Attributes (PAs). PAs were translated and extracted from each question which were stated in the questionnaires for 10 variables. In the case of variables, all the 9 Kano-SS questions were then translated into 9 PAs and inserted to QFD Step 1. 
Service Complaint (SCaKano-Q, SCaKano-SS) Index based on Service Dissatisfaction (SD)

Service Compliment (SCiKano-Q, SCiKano-SS) Index based on Service Satisfaction (SS)
PHASE 2: Patient Attributes PA (Kano-QFD Step 2-3)

PHASE 3: Matrix development (Kano-QFD Step 4-9)

Step 4: Defining the Healthcare Service Attributes (SA)

Step 5: Establishing the Relationship Matrix of PA \&SA

Step 6: Establishing the Relationship Matrix between SA

Step 7 \& 8: Calculating the index of PA \& SA

Step 9: Prioritized Service Attribute (SA)

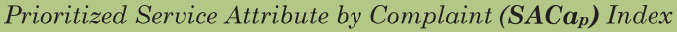

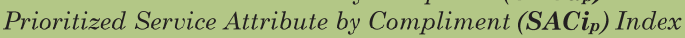

Prioritized Effective Service Attribute $\left(\mathbf{S A}_{\text {eff }}\right)$ Index $S A_{\text {eff }}=\left[\left(S A C a_{p}\right)^{2}+\left(S A C i_{p}\right)^{2}\right]^{1 / 2}$

Fig. 1. The flow of Kano-QFD execution for Phase 2 and 3

\subsection{Service Compliment and Service Complaint Indexes (Step 2)}

The index of $S C a$ and $S C i$ were inserted into QFD Step 2 based on the defined PAs, orderly. Figure 2 shows the information of PAs, $S C i$, and $S C a$ that was supplied to QFD Phases 2 and 3.

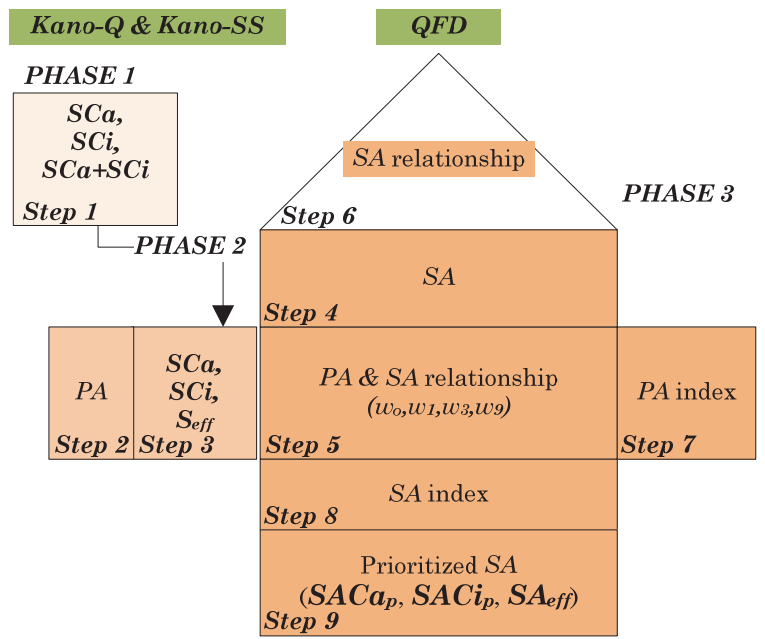

Fig. 2. The flow of information from Kano-QFD Step 1 to Step 2

On the VOPs side or patient's attributes $(P A \mathrm{~s})$, the introduction of prioritized patient's attributes by compliments $\left(P A C i_{p}\right)$ and complaints $\left(P A C i_{p}\right)$ had been applied. In terms of provided service by healthcare organization or service attributes $(S A \mathrm{~s})$, the formulation of $P A C i_{p}$ and $P A C a_{p}$ were then used for the introduction of prioritized service attributes by compliments $\left(S A C i_{p}\right)$ and complaints $\left(S A C a_{p}\right)$.

\subsection{Berger's Coefficient and Kano Attribute Category}

The service complaint index based on service dissatisfaction $\left(S C a_{K a n o-Q}, S C a_{K a n o-S S}\right)$ and service compliment index $\left(S C i_{\text {Kano-Q }}, S C i_{K a n o-S S}\right)$ based on service satisfaction had been determined by Berger's coefficient. To address the Berger's coefficient in standard form, the Eq. (1-6) can be rewritten as 


$$
\begin{aligned}
& S C a_{\text {Kano-Q }}=-\frac{(M+O)}{(A+M+O+I)} \\
& S C i_{\text {Kano-Q }}=\frac{(A+O)}{(A+M+O+I)} \\
& S D_{S S}=S C a_{\text {Kano-SS }}=-\frac{(M+O)}{(A+M+O+I)} \\
& S S_{S S}=S C i_{\text {Kano-SS }}=\frac{(A+O)}{(A+M+O+I)}
\end{aligned}
$$

Therefore, the design Kano-SS functional and dysfunctional agreement can be outlined as Kano-SS Functional Agreement,

$$
\sum_{i=1}^{n} A+\sum_{i=1}^{n} O \geq \sum_{i=1}^{n} M \text { or } \sum_{i=1}^{n} I
$$

and Kano-SS Dysfunctional Agreement,

$$
\sum_{i=1}^{n} M \text { or } \sum_{i=1}^{n} O>\sum_{i=1}^{n} A \text { or } \sum_{i=1}^{n} I
$$

\section{Results and Findings}

\subsection{Average of Service Satisfaction Index}

The satisfaction and dissatisfaction levels were based on the satisfaction and dissatisfaction coefficient. Table 2 presents the average service satisfaction coefficient $S S_{S S}$ and service dissatisfaction $S D_{S S}$ co-

\begin{tabular}{|c|c|c|c|c|}
\hline \multirow[b]{2}{*}{ Service variable (SV) } & \multicolumn{3}{|c|}{ Average service coefficient } & \multirow{2}{*}{$\begin{array}{l}\text { Service Satisfaction leve } \\
\text { (scale) } \\
\text { Anderson et al., } 2001\end{array}$} \\
\hline & $\begin{array}{c}\text { Satisfaction } \\
S S_{S S}\end{array}$ & $\begin{array}{c}\text { Dissatisfaction } \\
S D_{S S} \\
\end{array}$ & Actual & \\
\hline Doctor care & 0.31 & -0.57 & -0.26 & 3: Quite Dissatisfied \\
\hline Nurse care & 0.20 & -0.57 & -0.37 & 2: Dissatisfied \\
\hline Surgery care & 0.31 & -0.58 & -0.27 & 3: Quite Dissatisfied \\
\hline Doctor attitude \& personality & 0.33 & -0.59 & -0.26 & 3: Quite Dissatisfied \\
\hline Nurse attitude $\&$ personality & 0.23 & -0.56 & -0.33 & 2: Dissatisfied \\
\hline Appointment & 0.25 & -0.57 & -0.32 & 3: Quite Dissatisfied \\
\hline Medical communication & 0.24 & -0.58 & -0.34 & 2: Dissatisfied \\
\hline Admission & 0.22 & -0.56 & -0.34 & 2: Dissatisfied \\
\hline Discharge & 0.24 & -0.53 & -0.29 & 3: Quite Dissatisfied \\
\hline Mortuary & 0.28 & -0.46 & -0.18 & 2: Dissatisfied \\
\hline Average & 0.261 & -0.557 & & \\
\hline
\end{tabular}
efficient for all service variables. The highest satisfaction average service coefficient was Doctor Attitude and Personality with index 0.33 . The satisfaction level was based on the service satisfaction scale (1-7), as stated in the Kano-SS questionnaire.

\section{Table 2}

Average of service satisfaction index 


\section{Conclusion}

The aforementioned problems in our healthcare system will definitely become the root source of any potential dissatisfaction among healthcare customers, specifically patients. Table 3 summarizes the discussions on the healthcare capacity and constraints in Malaysia when compared to other countries. Table 3 also highlights that capacity and constraints in Malaysian healthcare service incur more complaints in local public healthcare service delivery.

\section{Table 3}

Summary of healthcare capacity and constraints

\begin{tabular}{ll}
\hline Author & Capacity and Constraints \\
\hline $\begin{array}{l}\text { Carnevalli \& Mi- } \\
\text { guel, (2008) }\end{array}$ & Malta, 1,600 general hospital beds to provide acute care with ratio 1:225 persons \\
$\begin{array}{l}\text { Powell \& Laufer, } \\
2010\end{array}$ & $\begin{array}{l}\text { In the United States, rapid medical technological advancement and unsustainable inflation in the } \\
\text { cost of care }\end{array}$ \\
$\begin{array}{l}\text { Onn et al., 2011 } \\
\text { Abdullah et al., }\end{array}$ & $\begin{array}{l}\text { In 2009, Singapore; 26 beds per 10,000 population while Malaysia; 17.06 per 10,000 population } \\
\text { Sector, inadequate expertise in some critical areas, and difficulty in placement and retention of } \\
\text { doctors and nurses in more remote areas }\end{array}$ \\
$\begin{array}{l}\text { Abdel Hakim } \\
\text { Rateb et al., 2011 }\end{array}$ & $\begin{array}{l}\text { Internal and external forces such as reimbursement changes, political landscape, and economic } \\
\text { changes }\end{array}$ \\
Baba, 2011 & $\begin{array}{l}\text { Australia with 22 million populations had 737 public and } 561 \text { private acute hospitals, whereas } \\
\text { Malaysian with a population of 28,676,201 million only had 133 public and 201 private acute care } \\
\text { hospitals }\end{array}$ \\
\hline
\end{tabular}

Hence, the failure to deliver service that meets the expectations of patients caused dissatisfaction in the form of complaints (Cheng Lim \& Tang, 2000). The factor of satisfaction is also neglected. In addition, the findings retrieved by Friman and Edvardsson (2003) in a study on satisfying and unsatisfying attributes in public transport services revealed that the aspect of compliment should also be configured to evaluate service perception in services. Similarly, Staniszewska and Henderson (2005) stressed that in healthcare service domain, patients' evaluation could be positive, despite the poor care due to loyalty. However, Anderson et al. (2001) believed that studying patient dissatisfaction is a more valuable concept than studying patient satisfaction.

This particular study examined the problem of intensifying complaints frequency towards local public hospital service delivery. Using linear assumption, the escalating complaints were mainly due to poor service delivery. However, this assumption is not always true due to the unexpected, uncertain, and hidden expectations of patient's fulfillment, which may not be effectively accounted for in the practice of service delivery improvement. This study also researched unaccounted patient's fulfillment which was measured via non-linear behavior assumption. In order to achieve efficacy, complaints and compliments were considered simultaneously during patient's dissatisfaction and satisfaction assessment. In this case, Kano's model was adapted and modified to synchronize with the above assumption. Besides, a new algorithm was developed for a non-linear quality attributes assessment. In sum, this study successfully discussed in length on the proposed Kano-QFD satisfaction model and reviewed findings, particularly on the strengths and weaknesses of the model. Suggestions and recommendations for future research are also proposed for further improvements on the model. It can be concluded that the present Malaysian healthcare capacity and constraints necessitate some of the reasons for complaints on service delivery dissatisfaction in Malaysian healthcare service. Thus, in order to reduce the frequency and address complaints appropriately, an investigation on the practice service delivery performance based on levels of dissatisfaction and satisfaction which are pertinent to complaints and compliments is deemed as necessary. 


\section{Acknowledgement}

The authors would like to thank the anonymous referees for constructive comments on earlier version of this paper.

\section{References}

Abdel Hakim Rateb, S., Abdel Razek El Nouman, A., Abdel Hakim Rateb, M., Naguib Asar, M., Mohammed El Amin, A., abdel Aziz Gad, S., \& Salah Eldin Mohamed, M. (2011). Re-engineering pre-employment check-up systems: a model for improving health services. International Journal of Health Care Quality Assurance, 24(6), 484-497.

Abdullah, N.H., Onn, L.T., Baba, N., \& Ahmad, M.K.S. (2011). Sivasampu S. National Healthcare Establishments and Workforce Statistics (Hospital) 2008-2009. In: Clinical Research Centre MoHM, editor. Kuala Lumpur: The National Healthcare Statistics Initiative (NHSI), p. 109.

Anderson, K., Allan, D., \& Finucane, P. (2001). A 30-month study of patient complaints at a major Australian hospital. Journal of Quality in Clinical Practice, 21(4), 109-111.

Baba, N. (2011). Managing Public Complaints for Service Delivery Excellence. In: Practice M, editor.: Ministry of Health, p. 1-34.

Baba, N., Chong, T.S., Ibrahim, L., Salleh, A.R., Mokhtar, L.M., \& Ali, A. (2011). Hospitals services in Malaysia. In: Sivasampu S, Lim TO, Hisham AN, editors. National Healthcare Establishments and Workforce Statistics 2008-2009. 1. 1 ed. Kuala Lumpur: Clinical Research Centre, Ministry of Health Malaysia; p. 109.

Camilleri, D., \& O’Callaghan, M. (1998). Comparing public and private hospital care service quality. International Journal of Health Care Quality Assurance, 11(4), 127-133.

Carnevalli, J. A., \& Miguel, P. C. (2008). Review, analysis and classification of the literature on QFDTypes of research, difficulties and benefits. International Journal of Production Economics, 114(2), 737-754.

Cheng Lim, P., \& Tang, N. K. (2000). A study of patients' expectations and satisfaction in Singapore hospitals. International Journal of Health Care Quality Assurance, 13(7), 290-299.

Cheng Lim, P., \& Tang, N. K. (2000). The development of a model for total quality healthcare. Managing Service Quality: An International Journal, 10(2), 103-111.

Chen, M. C., Chang, K. C., Hsu, C. L., \& Yang, I. C. (2011). Understanding the relationship between service convenience and customer satisfaction in home delivery by Kano model. Asia Pacific Journal of Marketing and Logistics, 23(3), 386-410.

Coye, R. W. (2004). Managing customer expectations in the service encounter. International Journal of service industry management, 15(1), 54-71.

Friman, M., \& Edvardsson, B. (2003). A content analysis of complaints and compliments. Managing Service Quality: An International Journal, 13(1), 20-26.

Gandhi, S., Sachdeva, A \& Gupta, A. (2018). Distributor service quality in Indian SMEs: A bidirectional customer perspective. Uncertain Supply Chain Management, 6(4), 335-356.

Grönroos, C. (1984). A service quality model and its marketing implications. European Journal of marketing, 18(4), 36-44.

Kano, N. (1984). Attractive quality and must-be quality. Hinshitsu (Quality, The Journal of Japanese Society for Quality Control), 14, 39-48.10. Rashid MM. A review of state of art on Jané, A. C., \& Domínguez, S. M. (2003). Citizens' role in health services: satisfaction behavior: Kano's model, part 1. Quality Management in Healthcare, 12(1), 64-71.

Henneberg, S. C., Gruber, T., Reppel, A., Ashnai, B., \& Naudé, P. (2009). Complaint management expectations: An online laddering analysis of small versus large firms. Industrial Marketing Management, 38(6), 584-598. 
Jangland, E., Gunningberg, L., \& Carlsson, M. (2009). Patients' and relatives' complaints about encounters and communication in health care: evidence for quality improvement. Patient education and counseling, 75(2), 199-204.

Löfgren, M., Witell, L., \& Gustafsson, A. (2011). Theory of attractive quality and life cycles of quality attributes. The TQM Journal, 23(2), 235-246.

Mohd Suki, N., Chiam Chwee Lian, J., \& Mohd Suki, N. (2011). Do patients' perceptions exceed their expectations in private healthcare settings?. International Journal of Health Care Quality Assurance, 24(1), 42-56.

Namkung, Y., Jang, S. S., \& Choi, S. K. (2011). Customer complaints in restaurants: Do they differ by service stages and loyalty levels?. International Journal of Hospitality Management, 30(3), 495502.

Onn, L.T., Sivasampu, S., Ariza, Z. (2011). Overview of hospitals and specialists services in Malaysia. In: Sivasampu S, Lim TO, Hisham AN, editors. National Healthcare Establishments and Workforce Statistics 2008-2009. 1. 1 ed. Kuala Lumpur: Clinical Research Centre, Ministry of Health Malaysia, p. 109.

Mikulić, J., \& Prebežac, D. (2011). A critical review of techniques for classifying quality attributes in the Kano model. Managing Service Quality: An International Journal, 21(1), 46-66.

Minas, H., Zamzam, R., Midin, M., \& Cohen, A. (2011). Attitudes of Malaysian general hospital staff towards patients with mental illness and diabetes. BMC public health, 11(1), 317.

Parasuraman, A. (2002). Service quality and productivity: a synergistic perspective. Managing Service Quality: An International Journal, 12(1), 6-9.

Powell, P. T., \& Laufer, R. (2010). The promises and constraints of consumer-directed healthcare. Business Horizons, 53(2), 171-182.

Quaschning, K., Körner, M., \& Wirtz, M. (2013). Analyzing the effects of shared decision-making, empathy and team interaction on patient satisfaction and treatment acceptance in medical rehabilitation using a structural equation modeling approach. Patient education and counseling, 91(2), 167175.

Rastgar, A \& Naderi, R. (2016). Evaluating pressures for green supply chain management adoption by grey theory approach. Decision Science Letters, 5(3), 417-430.

Staniszewska, S. H., \& Henderson, L. (2005). Patients' evaluations of the quality of care: influencing factors and the importance of engagement. Journal of Advanced Nursing, 49(5), 530-537.

Scott, D. J. (2003). Understanding and coping with complaints: a clinician's view. Current Paediatrics, 13(5), 376-381.

Shikiar, R., \& Rentz, A. M. (2004). Satisfaction with medication: an overview of conceptual, methodologic, and regulatory issues. Value in Health, 7(2), 204-215.

Singh Gaur, S., Xu, Y., Quazi, A., \& Nandi, S. (2011). Relational impact of service providers' interaction behavior in healthcare. Managing Service Quality: An International Journal, 21(1), 67-87.

Teck, C.H. (2007). Complaint Redressal System: The Public Complaints Bureau (PCB)., Prime Minister's Department, Malaysia. 10th Asian Ombudsman Association Conference; 25-28 April 2007; Hanoi, Vietnam, p. 1-11.

Wan, L. C. (2013). Culture's impact on consumer complaining responses to embarrassing service failure. Journal of Business Research, 66(3), 298-305.

Wah, T.W. (2011). Public complaints as source of innovation for goverment. Journal of Excellence, $3(1), 12-21$.

Wu, L., \& Norman, I. J. (2006). An investigation of job satisfaction, organizational commitment and role conflict and ambiguity in a sample of Chinese undergraduate nursing students. Nurse Education Today, 26(4), 304-314.

Wah, T. W. The 12th Conference of the Asian Ombudsman Association (AOA) 
Yuksel, A., Kilinc, U., \& Yuksel, F. (2006). Cross-national analysis of hotel customers' attitudes toward complaining and their complaining behaviours. Tourism Management, 27(1), 11-24.

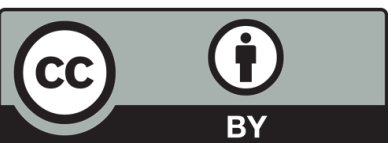

(C) 2018 by the authors; licensee Growing Science, Canada. This is an open access article distributed under the terms and conditions of the Creative Commons Attribution (CC-BY) license (http://creativecommons.org/licenses/by/4.0/). 